\title{
Early diagnosis of ALS: The search for signs of denervation in clinically normal muscles
}

\author{
Paul J. Blijham ${ }^{a, *}$, H. Jurgen Schelhaas ${ }^{b}$, Henk J. ter Laak ${ }^{c}$, \\ Baziel G.M. van Engelen ${ }^{\mathrm{b}}$, Machiel J. Zwarts ${ }^{\mathrm{a}}$ \\ a Department of Clinical Neurophysiology, Institute of Neurology, Radboud University Nijmegen Medical Centre, Nijmegen, The Netherlands \\ ${ }^{\mathrm{b}}$ Neuromuscular Centre Nijmegen, Institute of Neurology, Radboud University Nijmegen Medical Centre, Nijmegen, The Netherlands \\ ${ }^{\mathrm{c}}$ Neuromuscular Centre Nijmegen, Institute of Neurology and Pathology, Radboud University Nijmegen Medical Centre, Nijmegen, The Netherlands
}

Received 26 January 2007; accepted 5 July 2007

Available online 25 July 2007

\begin{abstract}
Aim and methods: We prospectively investigated whether early diagnosis of amyotrophic lateral sclerosis (ALS) could be facilitated by demonstrating signs of denervation in a muscle of a clinical and electromyographical unaffected region. Muscle fibre conduction velocity (MFCV) was determined in 18 patients in whom the diagnosis ALS was considered but not established beyond a level of clinically possible ALS according to the revised El Escorial criteria. A muscle biopsy was obtained from the same muscle, to demonstrate neurogenic changes. The study followed the guidelines from the STARD initiative.

Results and conclusion: Results were analysed with respect to the final diagnosis. After a mean follow-up of 16 months, 9 patients developed probable or definite ALS. Sensitivity of abnormal MFCV for developing ALS was $89 \%$. Muscle biopsy confirmed that denervation was the cause of abnormal MFCV. We concluded that MFCV can be used to detect denervation in muscles that show no clinical or electromyographical signs of lower motor neuron disease, and thus may contribute to early diagnosis of probable laboratory-supported ALS. (C) 2007 Elsevier B.V. All rights reserved.
\end{abstract}

Keywords: Amyotrophic lateral sclerosis; Electrodiagnosis; Denervation; Muscle biopsy; Muscle fibre conduction velocity; Muscle fibre diameter

\section{Introduction}

Needle electromyography (nEMG) can be an important contributor to early diagnosis of amyotrophic lateral sclerosis (ALS). Fibrillation potentials, positive waves, and abnormal motor unit potentials may indicate lower motor neuron (LMN) dysfunction prior to weakness or muscle atrophy $[1,2]$. According to the revised El Escorial criteria, such findings may lift the diagnosis from clinically possible ALS to clini-

Abbreviations: ALS, amyotrophic lateral sclerosis; EMG, electromyography; F/S, ratio fastest/slowest ratio; LMN, lower motor neuron; MFCV, muscle fibre conduction velocity; SD, standard deviation; UMN, upper motor neuron.

* Corresponding author. Department of Clinical Neurophysiology, Radboud University Nijmegen Medical Centre, P.O. Box 9101, 6500 HB Nijmegen, The Netherlands. Tel.: +31 24 3613491; fax: +31 243615097.

E-mail address: p.blijham@neuro.umcn.nl (P.J. Blijham). cally probably laboratory-supported ALS [3]. A clear definition of the stage of the disease is desirable for good clinical practice, and mandatory for research purposes. Nevertheless, in some patients with clinical signs or symptoms of possible ALS, evidence for LMN or upper motor neuron (UMN) disease in other regions cannot be found. These patients are faced with a period of uncertainty, because a diagnosis of ALS, or any other disorder, is usually only established after time has elapsed. In some of these patients, there is a need for a diagnostic technique that is capable of detecting changes in muscle tissue due to LMN disease, even before needle EMG can. Measurement of muscle fibre conduction velocity (MFCV) may be such an EMG technique. Increased fibre diameter variability can be an early sign of denervation [4], MFCV is related to fibre diameter in a linear fashion [5] and abnormal MFCV in muscles affected by motor neuron degeneration has been reported before [6]. 
In the present study, we prospectively estimated the diagnostic accuracy of MFCV in patients with possible ALS, or unexplained LMN symptoms. Measurements were made in a region that was clinically unaffected, and showed no nEMG signs of denervation. Muscle biopsies were obtained from the same muscle to verify the origin of abnormal findings. This study used the guidelines from the STARD initiative for studies on diagnostic techniques [7].

\section{Methods}

Patients were recruited from the Neuromuscular Centre Nijmegen, which is a secondary referral centre for patients with motor neuron disease. During a study period of 3 years, patients were consecutively included if they fulfilled the revised El Escorial (Airlie House) criteria of possible ALS, or if the underlying cause of LMN dysfunction in one or two regions could not be identified and ALS was considered. Clinically possible ALS was defined when clinical signs of UMN and LMN dysfunction were found together in only one region, or UMN signs were found alone in two or more regions; or LMN signs were found rostral to UMN signs and the diagnosis of clinically probable laboratory-supported ALS could not be proven by evidence on clinical grounds in conjunction with neurophysiologic, neuroimaging or clinical laboratory studies. Patients with a pure LMN syndrome in one or two regions were included if progressive muscle atrophy was present in at least 2 muscles, muscles not innervated by the same nerve or root, and in whom a diagnosis could not be established on clinical grounds in conjunction with neurophysiologic and neuroimaging studies.

Approximately 250 ALS patients were seen during the study period, and approximately $7 \%$ of these met the inclusion criteria of this study. Informed consent was asked before inclusion, and the study was carried out according to the Helsinki Principles.

Prior to inclusion, diagnostic needle EMG was performed according to established principles, by an experienced neurophysiologist. In the region that was to be studied, spontaneous muscle fibre discharges were absent, and motor unit potentials and interference pattern characteristics were within normal limits.

MFCV was obtained from a proximal muscle in a region that was clinically unaffected, and showed no evidence of LMN disease by nEMG examination. Thus, the quadriceps muscle was examined if the patient had UMN or LMN signs in an upper extremity, while the brachial biceps muscle was examined if the patient had UMN or LMN signs in a lower extremity. MFCV measurements were performed by the first author, who had not participated in the clinical and EMG examination prior to inclusion. MFCV was measured using a modified invasive technique [8,9]. Needle electrodes were used to evoke and record muscle fibre potentials. At least 25 muscle fibre potentials were recorded in each patient, which usually took about $15 \mathrm{~min}$. Mean MFCV was calculated using all fibres measured, and the ratio of slowest to fastest velocities ( $\mathrm{F} / \mathrm{S}$ ratio) was used to indicate scatter of velocities. A test was considered abnormal if either mean MFCV, or $\mathrm{F} / \mathrm{S}$ ratio, or both were abnormal. Normal values of our control population have been reported before (mean MFCV, $3.6 \mathrm{~m} / \mathrm{s}$; standard deviation (SD), $0.4 \mathrm{~m} / \mathrm{s} ; \mathrm{F} / \mathrm{S}$ ratio, $1.5 ; \mathrm{SD}$, $0.3 \mathrm{~m} / \mathrm{s}$ ) [8]. Cutoff values were set at $2 \mathrm{SD}$ below normal for mean $\operatorname{MFCV}(>2.8 \mathrm{~m} / \mathrm{s})$, and $2 \mathrm{SD}$ above normal for the $\mathrm{F} / \mathrm{S}$ ratio $(<2.2)$.

Following MFCV measurements, a needle muscle biopsy was obtained from the same muscle, and evaluated microscopically by a neuropathologist according to established principles. Muscle changes indicative of denervation were angular atrophic fibres of both fibre types, possibly combined with hypertrophic fibres with an increased number of internal nuclei. Fibre type grouping was considered a sign of reinnervation. Non-specific abnormalities included scattered

Table 1

Patient characteristics

\begin{tabular}{|c|c|c|c|c|c|}
\hline & $\begin{array}{l}\text { Age, } \\
\text { sex }\end{array}$ & $\begin{array}{l}\text { Symptoms at } \\
\text { presentation }\end{array}$ & $\begin{array}{l}\text { Time from } \\
\text { onset to } \\
\text { inclusion } \\
\text { (months) }\end{array}$ & $\begin{array}{l}\text { Follow-up } \\
\text { (months) }\end{array}$ & Final diagnosis \\
\hline 1 & $45, \mathrm{f}$ & $\begin{array}{l}\text { LMN arm+ } \\
\text { UMN leg }\end{array}$ & 40 & 20 & Definite ALS \\
\hline 2 & $64, \mathrm{f}$ & LMN legs & 16 & 20 & Definite ALS \\
\hline 3 & $61, \mathrm{~m}$ & $\begin{array}{l}\text { LMN bulbair, } \\
\text { UMN arm }\end{array}$ & 30 & 12 & Probable ALS \\
\hline 4 & $70, \mathrm{f}$ & $\begin{array}{l}\text { LMN legs, } \\
\text { UMN arm }\end{array}$ & 14 & 12 & Probable ALS \\
\hline 5 & $64, \mathrm{f}$ & $\begin{array}{l}\mathrm{LMN}+ \\
\mathrm{UMN} \text { legs }\end{array}$ & 11 & 15 & Probable ALS \\
\hline 6 & $50, \mathrm{f}$ & $\begin{array}{l}\mathrm{LMN}+ \\
\mathrm{UMN} \text { leg }\end{array}$ & 12 & 24 & $\begin{array}{l}\text { Probable ALS - } \\
\text { lab sup }\end{array}$ \\
\hline 7 & $71, \mathrm{~m}$ & $\begin{array}{l}\text { LMN leg+ } \\
\text { UMN arm }\end{array}$ & 5 & 12 & Probable ALS \\
\hline 8 & $67, \mathrm{~m}$ & $\begin{array}{l}\mathrm{LMN}+ \\
\mathrm{UMN} \text { leg }\end{array}$ & 12 & 14 & $\begin{array}{l}\text { Probable ALS - } \\
\text { lab sup }\end{array}$ \\
\hline 9 & $66, \mathrm{~m}$ & $\begin{array}{l}\mathrm{LMN}+ \\
\mathrm{UMN} \text { legs }\end{array}$ & 24 & 12 & UMN dominant ALS \\
\hline 10 & $65, \mathrm{~m}$ & $\begin{array}{l}\text { LMN legs, } \\
\text { ALS in family }\end{array}$ & 13 & 17 & $\begin{array}{l}\text { LMN of unidentified } \\
\text { cause }\end{array}$ \\
\hline 11 & $75, \mathrm{f}$ & LMN arm & 14 & 24 & $\begin{array}{l}\text { Monomelic } \\
\text { amyotrophy }\end{array}$ \\
\hline 12 & $60, \mathrm{~m}$ & $\begin{array}{l}\text { UMN arms } \\
\text { and leg }\end{array}$ & 48 & 12 & $\begin{array}{l}\text { Primary lateral } \\
\text { sclerosis }\end{array}$ \\
\hline 13 & $50, \mathrm{f}$ & $\begin{array}{l}\mathrm{UMN}+\mathrm{LMN} \\
\text { legs }\end{array}$ & 45 & 15 & $\begin{array}{l}\text { Primary lateral } \\
\text { sclerosis }+ \text { inclusion } \\
\text { body myositis } \\
\text { (biopsy proven) }\end{array}$ \\
\hline 14 & $56, \mathrm{~m}$ & $\begin{array}{l}\text { LMN arm, } \\
\text { generalized } \\
\text { fasciculations }\end{array}$ & 9 & 25 & $\begin{array}{l}\text { Cervical } \\
\text { radiculopathy }\end{array}$ \\
\hline 15 & $61, \mathrm{~m}$ & LMN arm & 24 & 10 & $\begin{array}{l}\text { Cervical } \\
\text { radiculopathy }\end{array}$ \\
\hline 16 & $47, \mathrm{~m}$ & $\begin{array}{l}\text { LMN both } \\
\text { arms, } \\
\text { UMN leg }\end{array}$ & 75 & 10 & $\begin{array}{l}\text { Cervical myelopathy } \\
\text { with bilateral } \\
\text { amytrophic diplegia }\end{array}$ \\
\hline 17 & $51, \mathrm{~m}$ & LMN arm & 7 & 21 & $\begin{array}{l}\text { Chronic progressive } \\
\text { plexopathy }\end{array}$ \\
\hline 18 & $35, \mathrm{~m}$ & $\begin{array}{l}\text { LMN legs, } \\
\text { ALS in family }\end{array}$ & 26 & 10 & $\begin{array}{l}\text { Restless legs } \\
\text { syndrome }\end{array}$ \\
\hline
\end{tabular}


Table 2

Diagnostic accuracy for MFCV and muscle biopsy for the diagnosis of probable, probable laboratory-supported, or definite ALS

\begin{tabular}{lllll}
\hline & $\begin{array}{l}\text { Sensitivity } \\
(\%)\end{array}$ & $\begin{array}{l}\text { Specificity } \\
(\%)\end{array}$ & $\begin{array}{l}\text { Positive } \\
\text { predictive } \\
\text { value }\end{array}$ & $\begin{array}{l}\text { Negative } \\
\text { predictive } \\
\text { value }\end{array}$ \\
\hline MFCV & 89 & 56 & 0.66 & 0.83 \\
Muscle biopsy & 78 & 89 & 0.88 & 0.80 \\
\hline
\end{tabular}

fibre hypertrophy with internal nuclei but without atrophy, the presence of a small number of necrotic fibres, and normal fibre diameters but other non-specific abnormal findings such as increased subsarcolemmal mitochondrial activity.

The follow-up period was at least 1 year. During the follow-up, patients were regularly seen by their neurologist, until a final diagnosis of ALS, or a different disorder could be established. The final diagnosis was based on consecutive clinical examinations, and repeated additional investigations, such as neuroimaging and EMG, excluding MFCV and biopsy results.

Sensitivity, specificity, positive and negative predictive values for a dichotomous diagnostic decision of ALS or no ALS, were determined for MFCV and for the muscle biopsy. A final diagnosis of ALS was defined as fulfilling the revised El Escorial criteria for clinically probable, probable laboratory-supported, or definite ALS.

\section{Results}

Eighteen patients were included: 10 with possible ALS, and 8 with LMN signs of unidentified cause in one or two regions. Clinical signs and symptoms, time from onset to presentation, and follow-up period after presentation are shown in Table 1. Eleven patients were male (mean age, 58 years; SD 10 years), and 7 female (mean age, 60 years; SD, 11 years). Nine studies of MFCV and biopsy were obtained from the quadriceps muscle, and 9 studies from the brachial biceps muscle. Mean time from onset to presentation was 23 months (range: 5-75), mean follow-up period was 16 months (range: 12-25). A final diagnosis of ALS was established in 9 patients ( 2 definite ALS, 4 probable ALS, 2 probable laboratory-supported ALS, and 1 UMN-dominant ALS). Two of these 9 patients died from ALS-related complications during the follow-up period. The final diagnosis of the patients who did not develop ALS are also shown in Table 1. In one patient with a positive family history for ALS, the cause of his cramps and fasciculations of the legs remained unidentified. This patient also suffered from restless legs syndrome.

Diagnostic accuracy of MFCV and muscle biopsy are shown in Table 2. Abnormal MFCV was found in 8 patients developing ALS, and in 3 patients of the non-ALS group (2 patients with primary lateral sclerosis, and 1 patient with a cervical radiculopathy). Denervation in the muscle biopsy was found in 7 patients developing ALS, and non-specific findings in the remaining 2 patients. Denervation was also seen in 1 patient of the non-ALS group (the patient with monomelic amyotrophy). Signs of reinnervation were found in 2 patients, 1 of whom developed probable laboratorysupported ALS.

Mean MFCV of the ALS group was $3.3(\mathrm{SD} 0.3 \mathrm{~m} / \mathrm{s})$, and of the non-ALS group 3.4 (SD $0.6 \mathrm{~m} / \mathrm{s})$, the difference being not significant. F/S ratio was 3.6 (SD 1.8) in the ALS group, and 2.6 (SD 1.6) in the non-ALS group, the difference being not significant. A specific pattern of abnormal conduction velocities on which the ALS and non-ALS groups could be discriminated was not found, although fibres tended to have slower MFCV in the ALS-group (Fig. 1).

\section{Discussion}

This study demonstrates that increased fibre diameter variability may indicate $\mathrm{LMN}$ dysfunction prior to muscle weakness, atrophy, or nEMG abnormalities in patients who eventually will develop ALS.

The patients included in this study represent a small but difficult group of patients who are referred to our clinic. In most patients, a diagnosis of ALS, or any other neurological

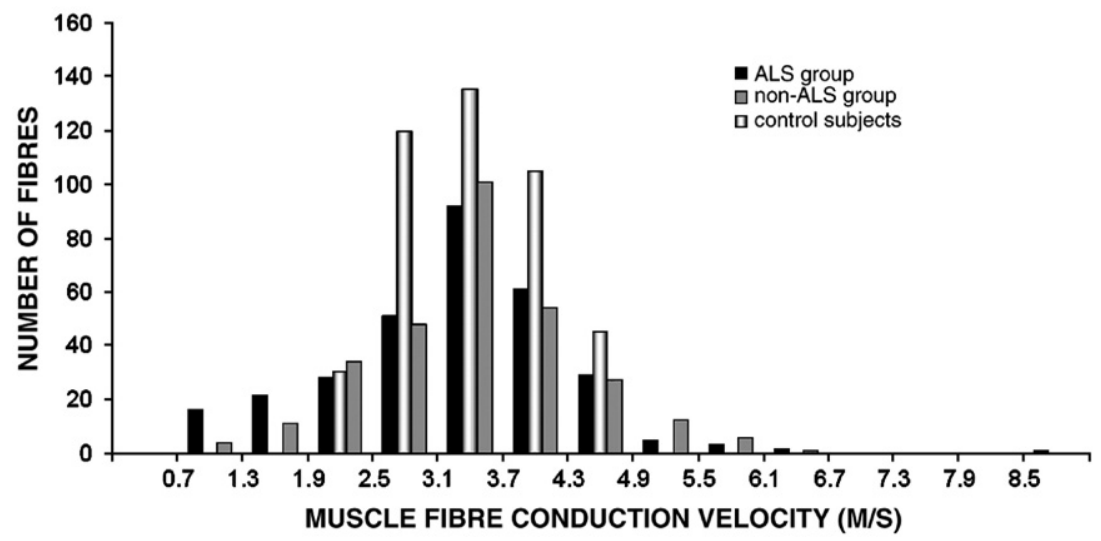

Fig. 1. Histogram of conduction velocities of all fibres pooled of the patients of the ALS-group, the non-ALS group, and of the normal values of our laboratory (scaled to fit). The increased conduction velocity variability is due to abnormal conduction both in the upper and the lower end. 
disorder, can usually be established after the first diagnostic work-up. This process can be frustrated however, by normal or inconclusive results from EMG and neuroimaging, especially if disease progression is slow. It is in these patients that MFCV studies may prove useful. Given the high negative predictive value, probable ALS is unlikely to develop if MFCV is normal. In such a case, other, possibly less devastating or even treatable disorders should be considered, such as cervical myelopathy, monomelic amyotrophy, or radiculopathy. Abnormal MFCV, when found in a clinical and electromyographical normal muscle in a patient in whom the diagnosis of ALS is considered, should be regarded as evidence for a more widespread disease. In such a case, a muscle biopsy of the same muscle may be obtained to identify the cause of abnormal propagation velocity. If the biopsy findings are consistent with a progressive neurogenic disorder, the patient should be regarded as having probable laboratory-supported ALS, and treated as such.

Slowing of propagation has been described in myopathies as well as in neurogenic disorders $[5,6,8]$. The slowly conducting fibres relate to atrophic fibres mainly, either due to denervation or due to myopathy, and may also represent early regenerating fibres. We also measured fast conducting fibres in both groups (Fig. 1), which very likely relate to large fibres, either due to neurogenic or (secondary) myopathic hypertrophy. A bimodal pattern of low and high conduction velocities, similar as to that of diameters in neurogenic disease, was not found. This suits the idea that the LMN disease was still in an early stage, before extensive reinnervation had taken place. The lack of specificity of slow or fast MFCV is a drawback of the technique.

In this regard, morphological data can be more specific. This was illustrated by the inflammatory signs found in the patient with inclusion body myositis, a disorder which should be recognized as an important mimic of ALS $[10,11]$.

Our data confirms the notion that muscle fibre diameter pathology needs to be rather severe before it is reflected in the motor unit action potential, as recorded with nEMG. A computer model that generates motor unit action potentials, predicted that an increase of the standard deviation of mean fibre diameter from $10 \mu \mathrm{m}$ (which is normal) to $30 \mu \mathrm{m}$ (which is pathological) resulted in a significant increase only of the number of turns and phases, but not of important parameters, such as amplitude and duration [12]. This implicates that nEMG is not a sensitive technique to detect changes in muscle, if these are only light to moderate. Given the subjective nature of routine nEMG investigations, it was stated that $n E M G$ is especially of diagnostic value if the changes are clear-cut, the examiner experienced, or both [13].

Although the El Escorial diagnostic criteria have been developed primarily for research purposes, good clinical practice also requires a clear definition of the stages of a disease. An accurate diagnosis of ALS in an early stage of the disease is important in the context of clinical trials, as well as for the recognition of disorders that may masquerade as ALS. Indeed, the application of the criteria may facilitate early recognition of non-ALS disorders in patients classified as possible ALS [11]. Our study suggests that in those patients in whom the normal work-up, including EMG, does not lift the diagnosis beyond possible ALS, further studies including MFCV and possibly muscle biopsy of an unaffected region can be performed to search for signs of denervation.

\section{Acknowledgement}

We would like to thank Dr. O.J. Vogels for his participation in the pilot of the present study.

\section{References}

[1] Daube JR. Electrodiagnostic studies in amyotrophic lateral sclerosis and other motor neuron disorders. Muscle Nerve 2000;231:1488-502.

[2] Swash M. Shortening the time to diagnosis in ALS: the role of electrodiagnostic studies. Amyotroph Lateral Scler Other Motor Neuron Disord 2000;1(suppl1):S67-72.

[3] Brooks BR, Miller RG, Swash M, Munsat TL, World Federation of Neurology Research Group on Motor Neuron Diseases. El Escorial revisited: revised criteria for the diagnosis of amyotrophic lateral sclerosis. Amyotroph Lateral Scler Other Motor Neuron Disord 2000;1:293-300.

[4] King Engel W. Muscle fibre regeneration in human neuromuscular disease. In: Mauro A, et al, editor. Muscle regeneration. 1st ed. New York: Raven Press; 1979. p. 287-8.

[5] Blijham PJ, Ter Laak HJ, Schelhaas HJ, Van Engelen BG, Stegeman DF, Zwarts MJ. Relation between muscle fibre conduction velocity and fibre size in neuromuscular disorders. J Appl Physiol 2006;100: $1837-41$

[6] Van der Hoeven JH, Zwarts MJ, Van Weerden TW. Muscle fibre conduction velocity in amyotrophic lateral sclerosis and traumatic lesions of the plexus brachialis. Electroencephalogr Clin Neurophysiol 1993;89:304-10.

[7] Bossuyt PM, Reitsa JB, Bruns DE, Gatsonis CA, Glasziou PP, Irwig LM, et al. Standards for reporting of diagnostic accuracy. Towards complete and accurate reporting of studies on diagnostic accuracy: the STARD initiative. BMJ 2003;326:41-4.

[8] Blijham PJ, Hengstman GJD, Ter Laak HJ, Van Engelen BGM, Zwarts MJ. Muscle-fibre conduction velocity and electromyography as diagnostic tools in patients with suspected inflammatory myopathy: a prospective study. Muscle Nerve 2004;29:46-50.

[9] Troni W, Cantello R, Rainero I. Conduction velocity along human muscle fibres in situ. Neurology 1983;33:1453-9.

[10] Rowland LP. Diagnosis of amyotrophic lateral sclerosis. J Neurol Sci 1998;160(suppl 1):S6-S24.

[11] Traynor BJ, Codd MB, Corr B, Forde C, Frost E, Hardiman O. Amyotrophic lateral sclerosis mimic syndromes: a population-based study. Arch Neurol 2000;57:109-13.

[12] Stålberg E, Karlsson L. Simulation of EMG in pathological situations. Clin Neurophysiol 2001;112:869-78.

[13] Fuglsang-Frederiksen A. The role of different EMG methods in evaluating myopathy. Clin Neurophysiol 2006;117:1173-89. 